\title{
Sertraline Induced Acute Hepatitis: A Case Report
}

\author{
Araz Aziz Abdullah 1*, Abdullah Saeed Ibrahim², Halgurd Fatihullah Ahmed ${ }^{3}$ \\ ${ }^{1}$ Department of Medicine, School of Medicine, Faculty of Medical Sciences, University of Sulaimani, \\ Sulaymaniyah, Iraq \\ ${ }^{2}$ Department of Medicine, College of Medicine, Hawler Medical University, Erbil, Iraq \\ ${ }^{3}$ Department of Medicine, Faculty of Medical specialties, Kurdistan Board for Medical specialties, Erbil, Iraq \\ Email: aras62@gmail.com, dr delmany@yahoo.com, halmaxa@yahoo.com, trainee@kbms.org
}

Received 14 December 2014; accepted 11 April 2015; published 20 April 2015

Copyright (C) 2015 by authors and Scientific Research Publishing Inc.

This work is licensed under the Creative Commons Attribution International License (CC BY). http://creativecommons.org/licenses/by/4.0/

c) (i) Open Access

\begin{abstract}
Depression is a common disorder amongst the general population and frequently encountered by most physicians. Selective Serotonin Re-Uptake Inhibitors (SSRI's) have become the most commonly prescribed antidepressants due to their superiority compared with other antidepressants in the treatment of acute major depression. Although exceedingly rare, hepatotoxicity resulting from sertraline use has been previously reported. In these case reports, the liver injury pattern was predominately hepatocellular. Unlike previous cases, we report the case of a patient presenting with markedly elevated cholestatic enzymes and painless jaundice while taking sertraline for treatment of depression.
\end{abstract}

\section{Keywords}

Sertraline, Obsessive-Compulsive Disorder, Acute Hepatitis

\section{Introduction}

Depression is a very common disorder amongst the general population and frequently encountered by most physicians. The international consortium of psychiatric epidemiology (ICPE) estimates the lifetime prevalence at $16.9 \%$ in the United States [1] and we anticipate a similar prevalence in Canada. Over the past twenty years, Selective Serotonin Re-Uptake Inhibitors (SSRI's) have become the most commonly prescribed antidepressants. Recent evidence suggests sertraline (a SSRI) may be superior in efficacy, acceptability, and tolerability compared with other antidepressants in the treatment of acute major depression [2]. Side effects of sertraline range from nau-

${ }^{*}$ Corresponding author. 
sea and vomiting, headache and tremors to sexual dysfunction. Asymptomatic elevations of transaminases have been documented in $0.8 \%$ of patients receiving sertraline [3]. Although exceedingly rare, hepatotoxicity resulting from sertraline use has been previously reported. A review of the literature revealed eleven prior reports of sertraline induced hepatotoxicity presenting with a predominately hepatocellular injury pattern or mixed obstructive and hepatocellular picture. Reported symptoms ranged from asymptomatic elevation of transaminases to fulminant hepatitis [4]-[7]. In these case reports, the liver injury pattern was predominately hepatocellular. Unlike previous cases, we report the case of a patient presenting with markedly elevated cholestatic enzymes and painless jaundice while taking sertraline for treatment of depression. We reported a young female with obsessive-compulsive disorder treated with sertraline-developed sertraline induced acute hepatitis.

\section{Background}

Sertraline (ser'tra leen) is a selective serotonin reuptake inhibitor (SSRI) that acts by blocking the reuptake of serotonin in CNS synaptic clefts, thus increasing serotonin levels in the brain which is associated with its psychiatric effects. Sertraline was approved for use in the United States in 1991, and it remains in wide use, with almost 40 million prescriptions being filled yearly [4]. Indications for sertraline include major depression, obsessive-compulsive disorder, panic disorder, and major anxiety disorders including social anxiety, post-trauma stress and generalized anxiety disorder [2]. Sertraline is also used for headache, premenstrual dysphoric disorder, diabetic neuropathy and premature ejaculation. Sertraline is available as tablets of 25,50 and $100 \mathrm{mg}$ and as an oral suspension in multiple generic forms and under the brand name of Zoloft. The recommended dosage for depression in adults is 50 or $100 \mathrm{mg}$ once daily, increasing the dosage by 25 or $50 \mathrm{mg}$ increments to a maximum of $200 \mathrm{mg}$ [7]. Common side effects are drowsiness, dyspepsia, nausea, headache, increased sweating, increased appetite, weight gain and sexual dysfunction [8].

\section{Literature Reveiw}

Christopher F describe that in rare instances of acute clinically apparent episodes of liver injury with marked liver enzyme elevations with or without jaundice been reported in patients on sertraline [4]. Croft $\mathrm{H}$ found that sertraline cause sexual dysfunction [3]. Other common side effects are drowsiness, dyspepsia, nausea, headache, increased sweating, increased appetite and weight gain which was described by sertraline's Product Information [2].

\section{Case Report}

Past medical history: only obsessive compulsive disorder, no any other medical condition.

This case is a rare side effect of sertraline, so scientifically and educationally better not to use this drug for long duration.

Usage of sertraline and increasing its dosage to large dose for about three years, treatment was done wrongly by the psychiatrist not the researchers. Just we observe its side effect and following her liver function test, when the liver injury had been happen by the drug.

What is important in this case her development of this serious liver injury and cleaned after six month, so scientifically it's necessary for psychiatrist be careful for about such a live threatening side effect of their drugs especially when they are using large dose for a long period.

A 46 years old south Asian female with diagnosis of obsessive compulsive disorder received sertraline (50 $100 \mathrm{mg}$ ) daily) for the last three years. In the last three months the dose increased to $150 \mathrm{mg} /$ day. Now she is presented with jaundice and pruritus for the last 2 weeks. The pruritus is generalized and it's more intense at night associated with dark urine, pale stool, epigastric pain, nausea, decrease appetite and fatigue, no fever, rash and loss of consciousness. There was no history of alcohol, antibiotic and herbal medication usage. Her clinical examination was unremarkable with no evidence of hepato-splenomegally or stigmata of chronic liver disease.

Liver Function Tests were significantly abnormal with consistent with acute liver injury, alkaline phosphatase $467 \mathrm{U} / \mathrm{L}$ (ref 80 - $290 \mathrm{U} / \mathrm{L}$ ), $\gamma$-glutamyl trans peptidase $100 \mathrm{U} / \mathrm{L}$ (4 - $38 \mathrm{U} / \mathrm{L}$ ), bilirubin $3.7 \mathrm{mg} / \mathrm{dl}(0-1.8 \mathrm{mg} / \mathrm{dl}$ ) mainly direct fraction, alanine transaminases (ALT) $99 \mathrm{U} / \mathrm{L}$ (ref 7 - $30 \mathrm{U} / \mathrm{L}$ ), aspartate transaminases (AST) 56 $\mathrm{U} / \mathrm{L}(10-50 \mathrm{U} / \mathrm{L})$.

Serial liver function tests after cessation of sertraline and during follow up were shown in Figures 1-3.

Other blood results including international normalized ratio and serum albumin were within the normal range. 
TSB

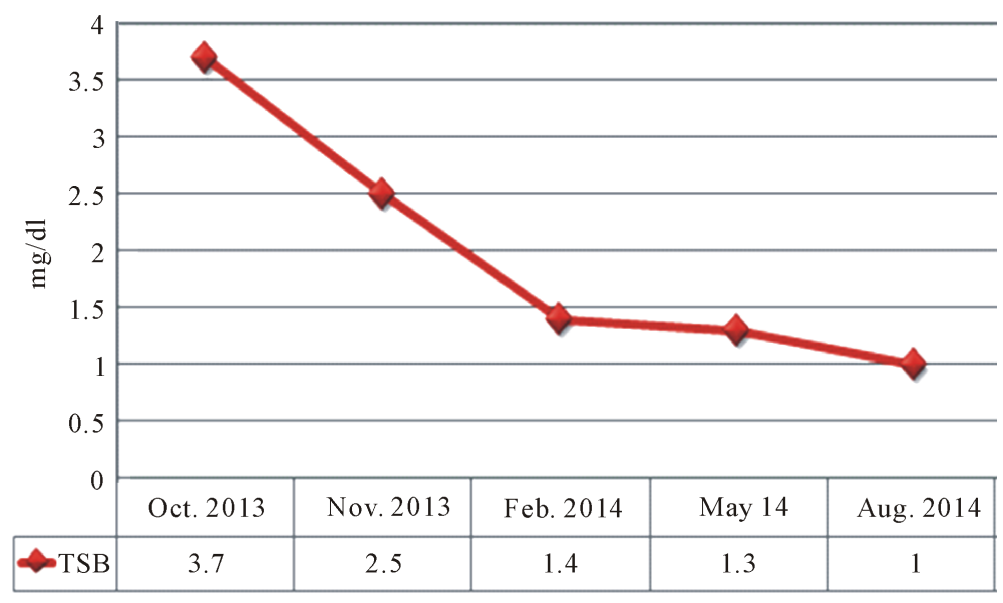

Figure 1. Dechallenge date total serum bilirubin.

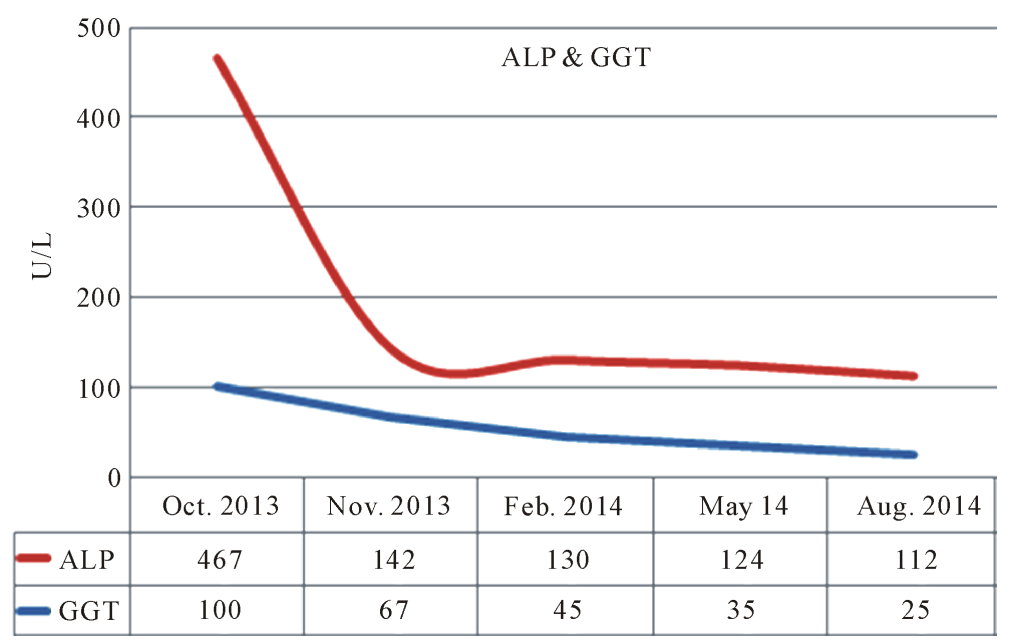

Figure 2. Dechallenge data serum alkaline phosphatase and $\gamma$-glutamyl trans peptidase.

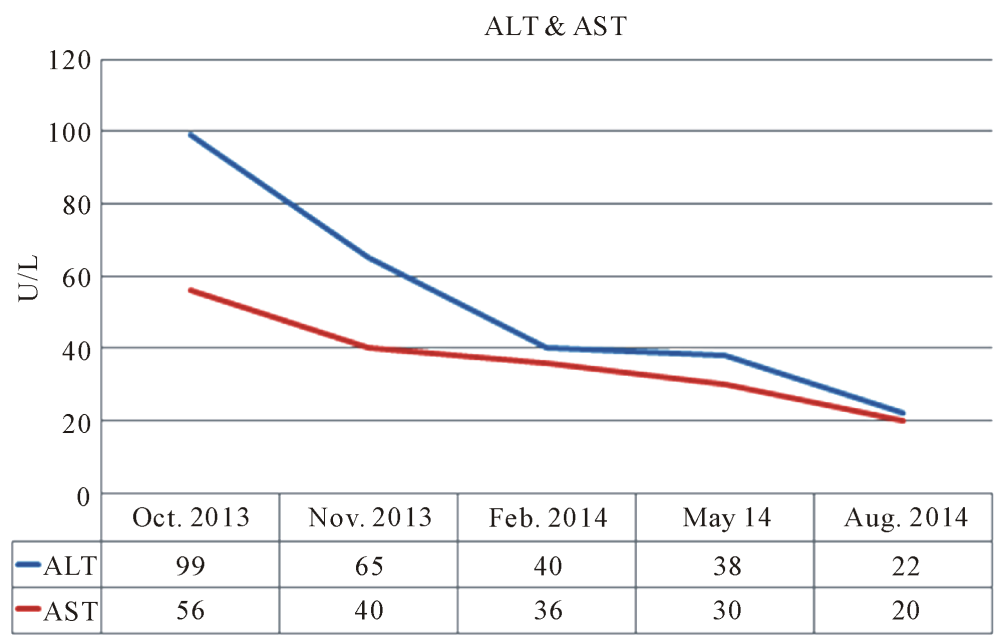

Figure 3. Dechallenge data serum alanine transaminases (ALT), aspartate transaminases (AST). 
Full blood count and morphology was normal with no evidence of eosinophilia.

A full blood screen was performed to determine the etiology of the liver derangement. Serology for hepatitis $\mathrm{A}, \mathrm{B}$, and $\mathrm{C}$ were negative, and an autoimmune screen for antinuclear antibody, ant smooth muscle antibody, anti-mitochondrial antibody, anti-liver kidney microsomal type-1 antibody and celiac antibodies were also negative.

In addition, iron studies, caeruloplasmin, and serum copper, protein electrophoresis and $\alpha-1$-antitrypsin levels were within the normal range. An abdominal ultrasound was unremarkable also with no evidence of hepatic or biliary pathology. She refused liver biopsy. Our patient's symptoms and liver biochemistry got improved following cessation of sertraline therapy.

\section{Discussion}

Sertraline is widely prescribed to treat depression and anxiety disorders. That is, the recommended dosage for depression in adults is 50 or $100 \mathrm{mg}$ once daily, but increasing the dosage by 25 or $50 \mathrm{mg}$ increments to a maximum of $200 \mathrm{mg}$ [2] [5] [6] is to be taken into account. Rare instances of acute, which are clinically apparent episodes of liver injury with marked liver enzyme elevations with or without jaundice, have been reported in patients on sertraline [7]. Compared with these classical antidepressants, SSRIs were thought to be less hepatotoxic [8]; the hepatotoxicity incidence of SSRIs is from 1.28 to 3.62 cases per "patient year" [9]. The onset of injury is usually within 2 to 24 weeks and the pattern of serum enzyme elevations has varied from hepatocellular to mixed and cholestatic. Autoimmune (autoantibodies) and immune allergic features (rash, fever, and eosinophilia) are uncommon. Acute liver failure due to sertraline has been described but very rarely [4] [6].

The patient's liver biochemical profile demonstrated increased liver enzymes, investigation failed to show any other pathology to account for her hepatitis. Liver function tests normalized after cessation of sertraline, indicating a probable association between sertraline use and acute hepatic injury in our patient.

While the mechanism by which sertraline causes hepatotoxicity is still not fully understood, a number of theories have been suggested. Proposed mechanisms include hepatotoxicity from sertraline or one of its metabolites, or an accumulation of sertraline in the body through inhibition of its own metabolism. Sertraline is metabolized at least in part by the liver mainly via the cytochrome P450 system and PYP 2D6 and 2B6, which can cause drug-drug interactions. The hepatotoxicity of sertraline may be mediated by toxic intermediates of their metabolism [5] [7] [8]. Recently, Li et al. postulated that mitochondrial dysfunction could play a role in sertraline-related liver injury through rapid cellular depletion of ATP in hepatocytes while also interfering with mitochondrial metabolism in a number of ways including the inhibition of mitochondrial respiration complexes [9]. The theory of an immunologically mediated hepatitis has also been suggested and is supported by the presence of eosinophils on liver biopsy and the idiosyncratic nature of the reaction [5] [10].

Also, numerous clinical adverse events involving liver toxicity have been reported during sertraline therapy, two of which cause severe hepatitis [7] [11]-[16].

In sertraline-induced hepatic injury, liver function typically improves soon after sertraline cessation. However, the time to normalization of liver function is variable and has been reported at 6 months following cessation of the drug [17]. Our case is consistent with previously reported cases with a time to resolution of 3-month post cessation of sertraline. In a case report of a 23 -year-old woman who developed hepatotoxicity from sertraline, Persky and Reinus noted that inadvertent rechallenge with sertraline resulted in a prompt rise in ALT, suggestive of an anamnestic response [15]. In the case of our patient, although recurrence following intentional rechallenge with sertraline would further support our diagnosis, this was not performed given the medical risks involved. The diagnosis of sertraline-induced hepatotoxicity requires a high index of suspicion, and awareness of the condition should be raised among all clinicians, in particular psychiatrists and general practitioners. If suspected, discontinuation of the medication is advised while other more common causes are excluded.

\section{Contributors}

All authors have contributed substantially to the conception, drafting and approval of the final version of the article.

\section{Conflict of Interest Declaration}

The authors have declared that they have no conflict of interest. 


\section{Patient Consent}

Written consent from patient was obtained.

\section{References}

[1] DeVane, C.L., Liston, H.L. and Markowitz, J.S. (2002) Clinical Pharmacokinetics of Sertraline. Clinical Pharmacokinetics, 41, 1247-1266. http://dx.doi.org/10.2165/00003088-200241150-00002

[2] Product Information (2012) Zoloft (Sertraline Hydrochloride) US Physician Prescribing Information. Pfizer, New York.

[3] Croft, H., Settle Jr., E., Houser, T., et al. (1999) A Placebo-Controlled Comparison of the Antidepressant Efficacy and Effects on Sexual Functioning of Sustained-Release Bupropion and Sertraline. Clinical Therapeutics, 21, 643-658. http://dx.doi.org/10.1016/S0149-2918(00)88317-4

[4] Christopher, F.D., Boyapati, R., Simpson, I., et al. (2013) Acute Liver Injury Secondary to Sertraline. BMJ Case Reports, 2, 21-29. http://dx.doi.org/10.1136/bcr-2013-201022

[5] Persky, S. and Reinus, J.F. (2003) Sertraline Hepatotoxicity: A Case Report and Review of the Literature on Selective Serotonin Reuptake Inhibitor Hepatotoxicity. Digestive Diseases and Sciences, 48, 939-944. http://dx.doi.org/10.1023/A:1023007831047

[6] Brahmania, M.S.Z., Rosenfeld, G. and Yoshida, E. (2011) Sertraline Induced Hepatotoxicity: A Case Report and Review of Literature. Internet $J$ Gastroenterol, 57, 987-989.

[7] Collados, V., Hallal, H. and Andrade, R.J. (2010) Sertraline Hepatotoxicity: Report of a Case and Review of the Literature. Digestive Diseases and Sciences, 55, 1806-1807. http://dx.doi.org/10.1007/s10620-010-1192-7

[8] Biour, M., Poupon, R., Grange, J.D., Chazouilleres, S.L., et al. (2002) He'patotoxicite' des me'dicaments: Mise a' jour $\mathrm{du}$ fichier bibliographique des atteintes he'patiques et des me'dicaments responsables. Gastroenterol. Clin. Biol., 16, 64-88.

[9] Li, Y., Couch, L., Higuchi, M., et al. (2012) Mitochondrial Dysfunction Induced by Sertraline, an Antidepressant Agent. Toxicological Sciences, 127, 582-591. http://dx.doi.org/10.1093/toxsci/kfs 100

[10] Devuyst, O., Lefebvre, C., Geubel, A., et al. (1993) Acute Cholestatic Hepatitis with Rash and Hypereosinophilia Associated with Ranitidine Treatment. Acta Clinica Belgica, 48, 109-114.

[11] Collados Arroyo, V., Plaza Aniorte, J., Hallal, H. and Pérez-Cuadrado, E. (2008) Hepatotoxicidad asociada a sertralina. Farmacia Hospitalaria, 32, 60-61. http://dx.doi.org/10.1016/S1130-6343(08)72814-9

[12] Fartoux-Heymann, L., Hézode, C., Zafrani, E.S., Dhumeaux, D. and Mallat, A. (2001) Acute Fatal Hepatitis Related to Sertraline. Journal of Hepatology, 35, 683-684. http://dx.doi.org/10.1016/S0168-8278(01)00159-3

[13] Hautekeete, M.L., Colle, I., van Vlierberghe, H. and Elewaut, A. (1998) Symptomatic Liver Injury Probably Related to Sertraline. Gastroentérologie Clinique et Biologique, 22, 364-365.

[14] Kim, K.Y., Hwang, W. and Narendran, R. (1991) Acute Liver Damage Possibly Related to Sertraline and Venlafaxine Ingestion. Annals of Pharmacotherapy, 33, 381-382. http://dx.doi.org/10.1345/aph.18155

[15] Persky, S. and Reinus, J.F. (2003) Sertraline Hepatotoxicity: A Case Report and Review of the Literature on Selective Serotonin Reuptake Inhibitor Hepatotoxicity. Digestive Diseases and Sciences, 48, 939-944. http://dx.doi.org/10.1023/A:1023007831047

[16] Verrico, M.M., Nace, D.A. and Towers, A.L. (2000) Fulminant Chemical Hepatitis Possibly Associated with Donepezil and Sertraline Therapy. Journal of the American Geriatrics Society, 48, 1659-1663.

[17] Tabak, F., Gunduz, F., Tahan, V., Tabak, O. and Ozaras, R. (2009) Sertraline Hepatotoxicity: Report of a Case and Review of the Literature. Digestive Diseases and Sciences, 54, 1589-1591. http://dx.doi.org/10.1007/s10620-008-0524-3 